\title{
What Happens to IT Education? The Case in Estonia with Some Recommendations for International Discussion
}

\author{
M. Pedaste, K. Kori, E. Tõnisson, T. Palts, H. Altin, and R. Rantsus
}

\begin{abstract}
The demand for IT skills and knowledge has increased worldwide, but nevertheless there is a shortage of programmers and other IT workers. To ensure the sustainability of the field it is necessary to change current IT educational practices and identify areas for improvement. This study, conducted in Estonia, focused on three aspects: IT students' source of interest in IT, their motivation to continue higher education IT studies and their motivation to graduate. A large-scale survey $(n=1374)$ involving most Estonian IT students in higher education was conducted. The results showed that sparking an interest in IT can already start at the general education level, where a more systematic approach is needed to introduce programming. In-service training and retraining for informatics teachers seems to be a solution. At the level of higher education, the primary factor influencing students' choice of curriculum was their interest in IT. In order to retain IT students, a solution offering students the chance to combine work and studies is needed. Work-related factors are the main predictors of students' dropout probability, while cognitive ability and motivation have a weaker effect. Based on this study in Estonia, some internationally applicable recommendations are made to different stakeholders.
\end{abstract}

Index Terms-Academic performance, IT education, study motivation, work experience, dropout.

\section{INTRODUCTION}

During the past decade, the demand for people with Information Technology (IT) skills and knowledge has increased worldwide [1]. To ensure the sustainability of the IT field it is important to change current IT educational practices and identify areas for improvement. This study focused on three aspects: IT students' source of interest in the IT field, their motivation to continue their higher education IT studies and their motivation to graduate.

In the European Union, the number of IT graduates has been decreasing since 2006, and forecasts show that by 2020 the shortage of IT workers could amount to 481,000-1,685,000 according to different scenarios [1]. Dropout of IT students is a problem worldwide (an average of $19 \%$ of students drop out in Europe according to Hüsing et al. [1]), but the issue is very serious in Estonia, where about $32 \%$ of IT students already drop out of higher education institutions during their first study year [2].

In Estonia, many of the students who do not finish their studies in IT still enter the labor market and find a job that

Manuscript received October 20, 2015; revised December 17, 2015.

The authors are with the University of Tartu, Ülikooli 18, Tartu 50090, Estonia (e-mail: margus.pedaste@ut.ee, kulli.kori@ut.ee, eno.tonisson@ut.ee, tauno.palts@ut.ee, heilo.altin@ut.ee, ramon.rantsus@ut.ee). requires IT knowledge and skills. It has been found that only half of the workers in the Estonian IT sector have a higher education degree in IT [3]. However, in the rest of the world, the proportion of workers with higher education degrees has increased in the IT sector [4]. So having a higher education degree leads to better chances in one's IT career. However, in case of an unmet demand for IT workers, many more countries might be affected by the Estonian problem of high dropout rates. Therefore, Estonia could be seen here as a case for studying the factors that influence student candidates' and students' motivation to study IT and their academic performance in order to make recommendations at an international level.

One of the factors influencing students' academic performance is cognitive ability [5]. Cognitive abilities can be defined as mental abilities that are needed in carrying out a task. These abilities can be measured through different intelligence tests, and strong correlations between students' academic performance and cognitive abilities have been revealed. For example, Lynn, Meisenberg, Mikk and Williams [6] found correlations from 0.83 to 0.92 between TIMSS and PISA test results and the average national IQ scores. The general effect of intelligence on educational achievement according to the meta-analysis by Sipe and Curlette [7] is around 0.6 and has generally been found to be stronger than the effect of motivation and several other factors.

Another factor that could influence academic performance is study motivation (see [8], [9]). Higher motivation can result in higher academic performance: e.g., Bruinsma [10] found that students with higher motivation earned more credit points, and Gottfried [11] linked higher motivation to lower dropout rates. More specifically, the motivation type also has an effect on academic performance and dropout [12]. Intrinsic motivation means that a person does something because it is inherently interesting or enjoyable, whereas extrinsic motivation makes a person do something because it leads to a separable outcome. A lack of intention to act suggests amotivation [13].

Both academic performance and academic motivation have an effect on students' dropout probability ([14] and study of authors, work in progress), but dropout in higher education can be influenced by many more factors (see [2]). Firstly, dropout is influenced by student demographics. Students who drop out are more likely to be male [15] and older [16], and they often have not entered higher education immediately after graduating high school [16], do not live in the same city where the university is located [17] and are married and have children [16]. Secondly, student income influences dropout students with a higher income are less likely to drop out [15], 
[18]. Working during studies helps to increase income, but it also increases the probability of dropping out, because working students have less time for studies [19], [20]. Thirdly, students with lower academic performance (lower average grade and fewer credit points) exhibit a higher probability of dropping out [15], [16], [18]. If a student plans to continue studying after receiving a Bachelor's degree [18] and his/her parents have a higher education degree as well [16], the dropout probability is lower. Fourthly, students who are more socially active and communicate more with fellow students and lecturers are less likely to drop out [18]. Also, it has been found that students' satisfaction with their studies leads to a greater likeliness of graduation [21], whereas stress and exhaustion decrease the probability of graduation [21]. Last but not least, there are some institutional characteristics that could influence dropout rates: student demographics, institution structure, faculty and finances [18].

Thus, there is plenty of research evidence that can be combined in order to make recommendations for improving the sustainability of the IT field. In our study, we first analyzed the literature that could help solve the issues concerning IT students' source of interest in the IT field, motivation to continue their higher education IT studies and motivation to graduate. Next, we collected additional data about Estonian students and made literature reviews and data reports available to experts in the IT field (educators in schools and universities, people from IT companies, policymakers). Justified recommendations were produced to improve IT education in Estonia. More specifically, the following research questions were formulated for this study:

1) What is the situation of IT education in Estonia?

2) How do different factors influence students' source of interest in the IT field, motivation to continue their higher education IT studies and motivation to graduate?

3) What kind of recommendations can be made to different stakeholders to improve IT education?

\section{METHODS}

Data for this study was collected in two ways: 1) large-scale surveys and 2) small-scale data collections regarding specific issues.

Data for the large-scale survey was collected from IT students who started their studies in the academic years 2013/2014 and 2014/2015. The sample of the study that started in 2013/2014 covered three Estonian higher education institutions and eight different IT related curricula (581 students in total). In 2014/2015, one more Estonian higher education institution and students from two IT related curricula were added to the sample (793 students in total). Altogether, data was collected from 1374 IT students. Already during the admission process, the student candidates answered a question about reasons choosing to study IT. After that, the students who were accepted to the higher education institutions filled in questionnaires at the beginning of each semester. The students who started in 2013/2014 responded to the questionnaire during two years (4 times), and the students who started in 2014/2015 did so during one year (2 times). The students filled in the questionnaires on paper during lectures (in order to increase the response rate); those who did not attend the lectures had the opportunity to fill in the questionnaires online. In addition, data was collected from universities about the students' academic performance (average grade and collected credit points) and dropout.

Two small-scale studies were also carried out. Firstly, 199 IT students in one higher education institution kept an online diary during one semester about the time they spent on studying in the university classes and outside of classes [22]. Secondly, phone interviews were conducted with some of the IT students who had dropped out. One Estonian higher education institution was in focus here; semi-structured phone interviews were carried out with 35 people who had studied IT in this higher education institution and dropped out during the first study year [23].

A descriptive data analysis was made with MS Excel and in-depth analysis with IBM SPSS Statistics 22 was used to compare different groups of students.

\section{RESUlTS AND DISCUSSION}

\section{A. Estonian Situation}

Sparking an interest in IT in young people can already start at the general education level, where no compulsory informatics subjects or courses are prescribed by the Estonian national curricula. Still, several elective IT subjects are taught in Estonian schools [24]. In general, three fields of specialization can be distinguished by IT education in Estonian schools: computer science (related to programming, robotics, etc.), regular user (texts, data, tables, presentations, etc.), and other subjects (related to the use of relevant programs and tools). The importance of developing digital skills is also underscored by the fact that starting from 2014, the Estonian national curriculum requires that a new general competence, digital competence, be developed in all subjects [25].

Since there are no state-level tests in IT subjects and no central learning materials, IT education in Estonian schools and its outcomes are not regulated by any specific requirements. According to the Estonian Education Information System [24], computer studies or informatics is taught in 397 basic schools out of 519 in Estonia (76.5\%), but in reality, similar subjects are taught in even more schools. There is even more diversity in upper secondary schools - less than half of the elective courses on computer studies taught in upper secondary schools stem from the list provided by the Estonian national curriculum [24]. Several fields of study in upper secondary schools are also connected with the IT field, e.g., information technology or STEM-oriented information technology. There might be greater focus on informatics in the STEM-oriented field, but even this is not known for certain. Also, some subjects are taught in Estonian upper secondary schools which, by their names, do not reveal the extent of their connection with IT: Technology, Multimedia, etc. In addition, there is great diversity in subjects related to programming - a dozen different programming languages are taught in Estonian schools [26]. In addition to the unspecified content of the informatics subject, there is also a shortage of qualified informatics teachers, since many teachers who are currently teaching this subject in Estonia have not studied 
informatics in a higher education institution, and it is even more rare that they have studied to become informatics teachers [27].

Besides general education schools, IT is also taught in vocational schools, universities and applied higher education institutions, but specializations are available in this case. In our study, the focus was on higher education IT studies (universities and applied higher education institutions). In Estonian higher education, regardless of the admission competition, practically all candidates are accepted to IT studies if they meet the minimum admission requirements set by the higher education institution (mostly results of the state exams, which do not directly reflect the person's professional capabilities, e.g., programming capabilities). Although there has actually been an admission competition in recent years, fewer students have ended up enrolling in the studies than the number of existing study positions in the curricula.

In the IT field, the roles and meanings of different types of education (vocational education, applied higher education, bachelor's studies, master's studies, and doctoral studies) are not quite clear. Students, IT companies, higher education institutions and other stakeholders can understand them differently, as well. This could lead to a situation where the same things are expected from applied higher education and bachelor's studies. Such duplication is not reasonable. Also, whereas employers generally tend to be happy with the specific IT skills of the IT graduates in Estonia, there is room for improvement in communication skills, learning skills, oral and written self-expression skills, basic entrepreneurship skills, etc. [28].

\section{B. Entering University}

Students enter university to study IT for different reasons. When student candidates were asked for the main reasons that influenced them to apply to an IT related curriculum, interest in IT $(55.4 \%)$, prior experience $(17.8 \%)$ and personal development (16.8\%) were the most popular answers [29]. Since interest was such a popular answer, students were asked at the beginning of the first semester about the defining moment that caused their interest in IT. Here, the most popular answer (36\%) was that the defining moment had been the chance to do something exciting on the computer [30]. Solving computer-related problems (helping others), building a computer, developing software or trying to make a computer game, web page design and even "breaking the computer" were listed as such activities. Moreover, $23 \%$ of the IT students reported that the defining moment had occurred already in childhood - in the primary school or even earlier. So, hands-on and creative experiences in working with a computer can get young people interested in IT. Such activities can be done at home, in school or in different hobby groups.

Also, 9\% of the IT students said that they opted for IT because someone was a role model for them or recommended the IT field [29]. Sometimes, a parent or friend who worked in IT was the role model, or a successful person they had heard about. Therefore, inviting people who work in the IT field to come and talk about their work in school could get students interested in studying IT at the higher education level.

Unfortunately, role models in the IT field are more often linked to aspects related to extrinsic motivation than intrinsic motivation. It is well known that salaries in the IT field are quite high, and IT students in Estonia are offered scholarships that are larger than in other fields. However, our study revealed that the majority of students enrolling in IT curricula did not consider the financial aspect (scholarship, future salary) as a particularly weighty reason for starting and continuing their IT studies [29]. Only a very small proportion of student candidates regarded the financial aspect as the reason for applying - high salaries in the IT field were mentioned by only $3.3 \%$ and bigger scholarships by $0.3 \%$ [29]. Other studies, too, have revealed that students enrolled in computer related curricula tend to assign less importance to their future salaries compared with other students [31]. At the same time, some studies have also shown that receiving financial support increases the probability of students finishing their studies [16], [18]. In our large-scale survey, however, the students' answers reveal that their expectations regarding the size of the scholarships are much higher than the scholarships that are currently paid to them. At the same time, the students' expectations will grow significantly by the second study year.

Still, every third high school graduate in Estonia admits that the decision about what to study tends to be rather incidental - and this is the case in Estonia in general and not specifically in the context of IT studies [32]. Also, the current study revealed that only a small proportion of students were well informed about their curriculum at the beginning of their studies [30]. So, students should be better informed about the curriculum before entering university. Also, it is a common understanding that studying IT only means programming. This is not true - even someone who is not that into programming or even afraid of it can find a topic of interest among the many IT subfields, and people with IT knowledge and skills are also needed in other fields, although programming skills are still important in all specializations. Here, a career advisor is needed, who helps the students make a conscious career choice.

\section{Studying IT and Academic Performance}

The students who started studying IT were mostly male (only 25\% were female) [30]. However, the proportion of women was significantly larger in one specific curriculum $44 \%$ of the students who enrolled in the Business Information Technology curriculum were women. So, this suggests that interdisciplinary curricula could be more attractive to female students.

In general, students' ratings of the accordance of their curriculum and studies (lecturers and study methods) with their expectations have been stable throughout two study years, but not particularly high (between 3.4 and 3.8 on a 5-point scale). So, there seems to be a gap between what the students expect and what the higher education institution offers. This could also be one of the reasons for students dropping out - the studies do not meet their expectations [21].

It was also found that those IT students who had previous experience in programming did better in their higher education studies than those with no past programming experience [33]. Previous programming experience gave the students an advantage in the first and second semester - those 
who had learned programming before had a higher average grade and considered their studies to be easier than those who first came into contact with programming in their higher education studies [2]. Other studies have also shown that the more programming languages a student has learned, the better he or she performs in tests and exams [34]. In addition to programming experience, learning mathematics in school also contributes to success in later IT studies, where mathematics becomes a necessity. The current study revealed that students who scored lower in the mathematics state exam were more likely to drop out in their first study year [2].

However, studies have shown that in the case of students with no previous experience in IT, pushing themselves and really making an effort allows them to achieve equal results compared to their peers. The small-scale study where students kept an online diary about the time they spent on studying revealed that spending more time on studying led to better academic results [22]. Good academic results are important: students who have poor grades and collect fewer credits are more likely to drop out [15], [16], [18]. It was also found that the learning environment factor, i.e. students' relationships with their peers and lecturers and participation in the IT community motivated them to continue their IT studies.

In Estonia, it is common that young people want to work while studying - a survey carried out in Estonia showed that $61 \%$ of students work during their studies [35]. As for IT students, earning extra money (42\%) and getting practice in the field $(28 \%)$ are the main reasons for working [30]. At the same time, studies have shown that the more hours per week students work, the higher the probability of dropping out [20]. With a high workload, students have less time for studying, which affects their academic performance [36].

\section{Dropout}

Phone interviews with the students who had dropped out of university during their first study year [23] revealed that many of them (40\%) started studying something else after dropping out of IT. $20 \%$ of the dropouts were working in the IT field with no IT education. Some (14\%) continued studying IT in a different curriculum or another higher education institution. The following reasons for dropping out were pointed out by the interviewees: $31 \%$ said that IT was not the right choice from their personal perspective; $21 \%$ had personal, health related or financial reasons; $17 \%$ found that studying in university did not meet their expectations; $17 \%$ considered the study load too high or subjects too complicated; $10 \%$ were working and did not have time for studying; and 5\% wished to study in a different IT curricula.

In addition to the interviews, some differences were detected in the large-scale survey between the students who dropped out and those who continued studying [2]. The students who dropped out had statistically significantly lower high school mathematics state exam results than their peers who did not drop out. The students who dropped out during the first study year considered their interest in IT to be lower than those who did not drop out. Also, the students who dropped out found the curriculum and the studies (teaching methods, lecturers, etc.) to be less in accordance with their expectations than their peers who continued studying. The dropouts also considered the university studies to be less pleasant compared to their peers who went on with their studies. Moreover, after the first semester, the future dropouts estimated the probability of them finishing their studies and working in the ICT field after graduation to be lower than their peers who continued studying.

Some differences were also revealed in the motivation of the students who dropped out and those who did not [2]. The dropouts were found to be less motivated to study and had lower scores in intrinsic motivation to know. This indicated that those who did not drop out studied more, because they wanted to gain new knowledge. The students who did not drop out had statistically marginally higher scores in one subcategory of extrinsic motivation - identified extrinsic motivation. This means that the students who did not drop out studied IT at the higher education level more, because they found IT studies valuable.

\section{E. Recommendations to Different Stakeholders Groups}

The literature review and additional data collection allowed the experts to make a number of recommendations. The recommendations were made to the following stakeholders, but do not need to be limited to them: primary and secondary education students, higher education students, parents, schools, higher education institutions, IT companies, and policymakers.

\section{1) Primary and secondary education students}

9 recommendations could be made:

1) Get involved in IT at an early age.

2) Try doing something on the computer yourself. A hands-on experience in working with a computer can get young people interested in IT.

3) Participate in an IT hobby group.

4) Before entering higher education, be sure about what you are going to study.

5) Choose your specialization based on your inner interest, not on potential financial gains.

6) Already in school, take the opportunity to learn programming and mathematics.

7) Enroll in higher education immediately after finishing high school.

8) Do not be afraid of moving to another city to study what you want, but make an informed decision. Check all higher education institutions for their IT curricula and then make an informed decision based on which curriculum suits you most.

9) Girls should not be afraid of studying IT.

Applying all these recommendations could have a positive effect on the number of student candidates in higher education institutions and their academic performance. But even more importantly, the recommendations help avoid making wrong decisions in starting one's higher education studies. A more informed, conscious decision by the student candidate helps the university be more effective in its admissions.

\section{2) Higher education students}

We can make 9 recommendations to students who are already studying IT in order for them to improve their study performance and prevent dropout:

1) Be consistent and finish your IT studies. Having a higher education degree will give you better chances in your 
career.

2) IT is not just programming - even someone who is not that into programming or even afraid of it can find a topic of interest among the many IT subfields.

3) Serious commitment to IT studies is essential for beginners to perform as well as their more experienced peers.

4) Even an experienced IT specialist must study hard at the higher education level, because studying hard is important for minimizing the risk of dropping out.

5) When working during your studies, keep your workload as low as possible. Higher workload is a predictor of dropout.

6) Balance your studies and family obligations.

7) Communicate with your fellow students to blend in with the IT community.

8) Consider enrolling in postgraduate studies after receiving your Bachelor's degree.

9) Try to avoid stress.

In conclusion, the recommendations show to the students the need to focus on their studies and find a balance between their different responsibilities (studies, work and family). However, it is easier if a strong community of students is formed that supports its peers and helps avoid stress.

\section{3) Parents}

Parents also have an important role in supporting their children in both general school and higher education. Therefore, we have produced several recommendations to them, as well:

1) Already at an early age, children should have the opportunity to do some hands-on activities on the computer.

2) Help your child pick a hobby group.

3) Parents should be more aware of what is going on in the digital world.

4) The role of parents is to actively ask for possibilities of learning IT for their children.

5) The digital competence is a general competence which all people should develop. So, the digital competence is also important for adults.

6) Do not worry too much about your child breaking the computer.

7) Let the children educate themselves in the IT field. This is a good way to value your children's skills, and it can really increase their self-belief and motivation.

8) Value higher education.

9) Students need financial support to focus on their studies.

Parents have two main roles here: to improve their own IT competencies in order to be a good supportive role model for their children and to support their children in looking for their field of interest around IT studies. The support is mainly psychological, but sometimes also financial.

\section{4) Schools}

Most schools in Estonia already provide IT studies to students through optional courses. Still, several recommendations can be made to improve the situation - the quality and content of the courses vary a lot, as there is no compulsory curriculum for IT studies:

1) High quality IT education should be available to students in all schools. We recommend thinking about how computer/informatics education is organized in your school and which support you would need to ensure that your students have access to good quality IT education.

2) Schools should provide their students with the opportunity to learn programming, or talented students who are interested in programming could be offered relevant courses outside of their schools.

3) The school career advisor should also introduce IT career possibilities to students, accept school visits and invite people from IT companies to teach lessons in school.

4) The school should support and take part in IT popularization activities, such as IT competitions.

5) To attract more girls to IT education, programming should be more integrated with other subjects.

6) Teachers should regularly and actively participate in IT trainings for teachers.

7) Teachers could use more IT tools in other classes as well.

Thus, schools should offer several possibilities for learning and guide students in making an informed decision about continuing their education. Therefore, not only IT teachers, but also all other teachers should be involved and act as role models in actively applying IT in their teaching.

\section{5) Higher education institutions}

While interest in IT studies is formed at public school level, higher education institutions are responsible for maintaining this interest and linking studies with the labor market. Therefore, we have also made a number of recommendations to higher education institutions:

1) Offering more flexible forms of study and being more profession oriented may contribute to greater interest by student candidates.

2) In order to increase the proportion of female students, offering more interdisciplinary and more flexible study possibilities should be considered.

3) In IT studies, attention should also be paid to general skills: communication skills, learning skills, self-expression skills, etc.

4) The curriculum and organization of studies should be negotiated more with different parties (e.g., IT companies)

5) In the admission process, it is important to ask about candidates' previous experience in programming, which significantly influences their study motivation and academic performance.

6) Special attention should be paid to supporting working students, as it is very hard for them to combine studies and work.

7) Collaboration with IT companies in organizing practice is needed.

8) Schools also need universities' help in offering IT education (programming, in particular).

9) University curricula and studies should be explained to the student candidates in more detail in order for them to make an informed decision about their future studies. Not being aware of the curricula and studies leads to a high risk of dropping out due to unmet expectations.

Thus, the analysis of literature and data from our study shows that higher education institutions should increase flexibility, offer practical activities together with IT 
companies and build a link between public schools and higher education by supporting IT studies in schools.

\section{6) IT companies}

IT companies also need to consider how they could support schools and universities to ensure the sustainability of the IT field. Recommendations to IT companies:

1) If you want to get specialists from higher education institutions instead of just workers with lower qualifications, do not attract students to positions with a high workload too soon.

2) It is important for students that employers value higher education and show the career opportunities it can bring.

3) Collaboration between universities and IT companies must continue and become more systematic.

4) IT companies should consider creating additional practical training positions for students.

5) The associations of IT companies have the important role of visiting schools to increase young people's awareness of IT education and job opportunities.

6) There is an actual need for a documentary about the IT industry. A documentary would bring the study and career opportunities available in the IT sector closer to students and make them more aware of the diversity of occupations in IT.

7) IT companies should contribute even more to IT hobby groups.

In conclusion, IT companies should have a significant role in collaborating with higher education institutions and schools to link labor market with education and increase motivation to study IT.

\section{7) Policymakers}

Policymakers have the power to create suitable conditions for other stakeholders (e.g., schools, higher education institutions, parents) for them to be able to implement the recommendations made to them. Therefore, based on the study, recommendations have been produced that can be taken into account when making decisions regarding the development of the IT field either on the national, local or school level. Below, we present our recommendations to policymakers, created on the basis of data collected in our study and recommendations made to other stakeholders, aimed at fostering the development of the IT field. The recommendations have been divided into four categories: content, tools, additional possibilities, and support.

\section{8) Content development}

1) IT education curricula in schools need revising. It should be in line with what is taught at higher education level and expected by IT companies.

2) External assessment of academic results in schools should also focus on assessing transferable skills, e.g., students' digital competencies.

3) The list of professional competencies of IT workers needs revising.

\section{9) Ensuring tools}

1) IT tools need to be available to everyone. Therefore, enough resources should be allocated to purchase and update these.

2) The existing IT tools should be used more for learning.
Therefore, teachers should be taught about effective methods of using IT in their teaching.

\section{0) Creating additional possibilities}

1) Enthusiasts need possibilities for specialization. Therefore, support for hobby groups is needed.

2) Flexible, interdisciplinary forms of study are needed. Students should have possibilities for learning IT in their own school, but studies in hobby schools or online (e.g., MOOCs) should also be recognized as forms of learning.

\section{1) Ensuring support}

1) Career coordinators or advisors have an important role in schools. They should be supported to increase students' awareness of different careers, including careers in IT.

2) Combining studies and work needs clear regulation. In the IT field, it is not easy to choose either studies or work, and regulation that supports combining these is needed.

3) Raising awareness of the IT field and popularization of IT requires decisive action.

According to these recommendations, policymakers should allocate resources to the supportive staff who could work with school children and university students to increase their understanding of the IT field, and regulations should be updated so that there are flexible options for studying IT.

\section{CONCLUSION}

The current study gave an overview of the situation of IT education in Estonia. The focus was on three aspects: IT students' source of interest in the IT field, their motivation to continue their higher education IT studies, and their motivation to graduate. Regarding these aspects, some problems were detected in Estonian IT education. Based on the results of large- and small-scale data collections, recommendations for improving the situation were made to primary and secondary education students, higher education students, parents, general education schools, higher education institutions, IT companies, and policymakers. The recommendations are relevant for Estonia to ensure the sustainability of the IT field, but also for other countries with similar problems. In future studies, it is important to find out how these recommendations work in Estonia and worldwide. In addition, the question about the role higher education institutions should take in comparison to vocational schools and companies when educating people for working in IT still remains open for discussion. Should graduates simply be shaped to meet the exact needs of IT companies or should students acquire deeper analytical and programming skills?

\section{ACKNOWLEDGMENT}

We wish to thank the entire project team (see http://ict.ut.ee) who actively participated in the different stages of the project.

This research was supported by the European Union through the European Regional Development Fund. It is financed in the project "Conceptual Framework for Increasing Society's Commitment in ICT: Approaches in General and Higher Education for Motivating ICT-Related Career Choices and Improving Competences for Applying and Developing ICT". 


\section{REFERENCES}

[1] T. Hüsing, W. B. Korte, N. Fonstad, B. Lanvin, D. Welsum, G. Cattaneo, M. Kolding, and R. Lifonti. (2013). E-leadership. E-skills for competitiveness and innovation vision, roadmap and foresight Scenarios final report. [Online]. Available: http://eskills-vision.eu/fileadmin/eSkillsVision/documents/VISION\% 20Final\%20Report.pdf

[2] K. Kori, M. Pedaste, E. Tõnisson, T. Palts, H. Altin, R. Rantsus, R. Sell, K. Murtazin, and T. Rüütmann, "First-year dropout in ICT studies," IEEE Global Engineering Education Conference, Tallinn University of Technology, Tallinn, Estonia: IEEE, pp. 444-452, 2015.

[3] A. Jürgenson, E. Mägi, K. Pihor, V. Batueva, H. Rozeik, and R. Arukaevu, "Mapping the current situation and needs of Estonian workforce with ICT competencies, (in Estonian)," Praxis, 2013.

[4] A. Sum, I. Khatiwada, and S. Palma, "Employment prospects in information technology jobs for non-college-educated adults," Challenge, vol. 50, no. 1, pp. 97-114, 2007.

[5] M. Pedaste, O. Must, G. Silm, K. Täht, K. Kori, Ä. Leijen, and M.-L. Mägi, "How do cognitive ability and study motivation predict the academic performance of IT students?" presented at ICERI Conference, 2015.

[6] R. Lynn, G. Meisenberg, J. Mikk, and A. Williams, "National IQs predict differences in scholastic achievement in 67 countries," Journal of Biosocial Science, vol. 39, pp. 861-874, 2007.

[7] T. A. Sipe and W. L. Curlette, "A meta-synthesis of factors related to educational achievement: A methodological approach to summarizing and synthesizing meta-analyses," International Journal of Educational Research, vol. 25, no. 7, pp. 583-698, 1996.

[8] S. B. Robbins, K. Lauver, H. Le, D. Davis, R. Langley, and A. Carlstrom, "Do psychosocial and study skill factors predict college outcomes?” A Meta-Analysis Psychological Bulletin, vol. 130, no. 2, pp. 261-288, 2004.

[9] J. S. Eccles and A. Wigfield, "Motivational beliefs, values, and goals," Annual Review of Psychology, vol. 53, pp. 109-132, 2002.

[10] M. Bruinsma, "Motivation, cognitive processing and achievement in higher education," Learning and Instruction, vol. 14, no. 6, pp. 549-568, 2004.

[11] A. E. Gottfried, "Commentary: The role of environment in contextual and social influences on motivation: Generalities, specificities and causality," Handbook of Motivation at School, New York: Routledge, pp. 462-475, 2009.

[12] B. Abar, C. C. Abar, M. Lippold, C. J. Powers, and A. E. Manning, "Associations between reasons to attend and late high school dropout," Learning and Individual Differences, vol. 22, pp. 856-861, 2012.

[13] R. M. Ryan and E. L. Deci, "Intrinsic and extrinsic motivations: Classic definitions and new directions," Contemporary Educational Psychology, vol. 25, pp. 54-67, 2000.

[14] R. J. Vallerand and R. Bissonnette "On the predictive effect of intrinsic, extrinsic, and amotivation styles on behaviour: A prospective study," Journal of Personality, vol. 60, pp. 599-620, 1992.

[15] F. Belloc, A. Maruotti, and L. Petrella, "How individual characteristics affect university students drop-out: A semiparametric mixed-effects model for an Italian case study," Journal of Applied Statistics, vol. 38, no. 10 , pp. 2225-2239, 2011

[16] L. S. Stratton, D. M. O'Toole, and J. N. Wetzel, "A multinomial logit model of college stopout and dropout behaviour," Economics of Education Review, vol. 27, pp. 319-331, 2008.

[17] G. Lassibille and L. N. Gomez, "Why do higher education students drop out? Evidence from Spain," Education Economics, vol. 16, no. 1, pp. 89-105, 2008.

[18] R. Chen, "Institutional characteristics and college student dropout risks: A multilevel event history analysis," Research in Higher Education, vol. 53, pp. 487-505, 2012.

[19] G. Taylor, N. Lekes, H. Gagnon, L. Kwan, and R. Koestner, "Need satisfaction, work-school interference and school dropout: An application of self-determination theory," British Journal of Educational Psychology, vol. 82, pp. 622-646, 2012.

[20] C. Polidano and R. Zakirova, Outcomes from Combining Work and Tertiary Study. A National Vocational Education and Training Research and Evaluation Program Report, National Centre for Vocational Education Research Ltd. PO Box 8288, Stational Arcade, Adelaide, SA 5000, Australia, 2011.

[21] L. C. Duque, "A framework for analysing higher education performance: Students' satisfaction, perceived learning outcomes, and dropout intentions," Total Quality Management, vol. 25, no. 1, pp. 1-21, 2014.
[22] M. Niitsoo, M. Paales, M. Pedaste, L. Siiman, and E. Tõnisson, "Predictors of informatics students' progress and graduation in university studies," in Proc. 8th International Technology, Education and Development Conference, Valencia, 2014, pp. 2521-2529.

[23] H. Altin and R. Rantsus, "Why students fail to graduate ICT-related curricula at university level?" in Proc. 9th International Technology, Education and Development Conference Madrid, 2015, pp 5364-5368.

[24] Estonian Education Information System (EHIS). (2015). Estonian Ministry of Education and Research. [Online]. Available: http://www.ehis.ee/

[25] National Curriculum for Upper Secondary Schools. (2011). Riigi Teataja I. [Online]. Available: https://www.riigiteataja.ee/akt/129082014021

[26] S. Puniste, "Programming courses in Estonian secondary schools," Bachelor thesis (in Estonian), Institute of Computer Science, University of Tartu, Tartu, 2015.

[27] M. Pedaste and M. Mäeots, "In-service training of teachers," External Evaluation Department of the Ministry of Education and Research (in Estonian), Tartu, pp. 102-105, 2011.

[28] R. Väljur, "Estonian entrepreneurs expectations of IT university graduates," Bachelor thesis (in Estonian), Institute of Computer Science, University of Tartu, Tartu, 2013.

[29] K. Kori, M. Pedaste, M. Niitsoo, R. Kuusik, H. Altin, E. Tõnisson, I Vau, Ä. Leijen, M. Mäeots, L. Siiman, K. Murtazin, and R. Paluoja, "Why do students choose to study Information and Communications Technology?” Procedia Social and Behavioral Sciences, vol. 191, pp 2867-282, 2015.

[30] K. Kori, H. Altin, M. Pedaste, T. Palts, and E. Tõnisson, "What influences students to study information and communication technology?" in Proc. 9th International Technology, Education and Development Conference Madrid, pp. 1477-1486, 2014.

[31] P. M. Alexander, M. Holmner, H. H. Lotriet, M. CMatthee, H. V. Pieterse, S. Naidoo, H. Twinomurinzi, and D. Jordaan, "Factors affecting career choice: Comparison between students from computer and other disciplines," Journal of Science Education and Technology, vol. 20, pp. 300-315, 2011.

[32] E. Mägi and M. Nestor, "School graduates and their career choices. Final report of a survey about secondary school graduates' choices," Praxis, SA Archimedes, 2012.

[33] K. Kori, M. Pedaste, Ä. Leijen, and E. Tõnisson, "The role of programming experience in ICT students' learning motivation and academic achievement," International Journal of Information and Education Technology, vol. 6, no. 5, pp. 331-337, 2016.

[34] D. Hagan and S. Markham, "Does it help to have some programming experience before beginning a computing degree program?" in Proc. the 5th Annual SIGCSE/SIGCUE ITiCSE Conference on Innovation and Technology in Computer Science Education, pp. 25-28, 2000.

[35] M. Beerkens, E. Mägi, and L. Lill, "University studies as a side job: Causes and consequences of massive student employment in Estonia," Higher Education, vol. 61, no. 6 pp. 679-692, 2011.

[36] M. Triventi, "Does working during higher education affect students' academic progression?" Economics of Education Review, vol. 41, pp $1-13,2014$.

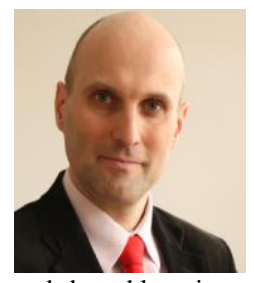

Margus Pedaste was born in Tartu, Estonia, in 1976. He is full professor of educational technology at the University of Tartu, where he is leading the Centre for Educational Technology and Pedagogicum of the university. He has worked as a science teacher in a general school and as a teacher educator at the university for 15 years. Prof. Pedaste received his $\mathrm{PhD}$ degree on the theme "Problem solving in web-based learning environments". He is also the main developer of many web-based learning environments and national or international coordinator of several research \& development grants.

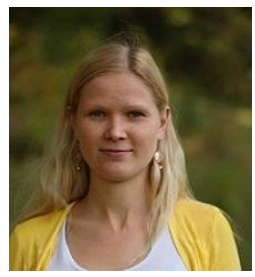

Külli Kori was born in Türi, Estonia, in 1989. She received her bachelor of science degree in 2011 and the master of arts degree in education (biology teacher) in 2013 from the University of Tartu, Estonia. Currently, she is a doctoral student in educational sciences at the University of Tartu, Estonia. She has been working as junior research fellow of Educational technology at the University of Tartu. Her research interests are how to motivate career choices in ICT and how to support ICT students. 


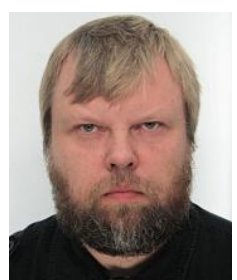

Eno Tõnisson was born in Tartu, Estonia, in 1969. He graduated as mathematics teacher in 1992 and received his master of science degree in mathematics in 1996 from the University of Tartu. His current research themes include use of computer algebra systems in mathematics education; didactics of programming; career choices of students of computer science and information technology. He has worked as a mathematics teacher in secondary school and as lecturer in the Institute of Computer Science of the University of Tartu.

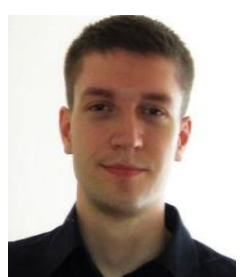

Tauno Palts was born in Rakvere, Estonia, in 1985 He graduated from Information Technology in 2009 and received his Master of Arts degree in Teacher of Mathematics and Informatics in 2011 from the University of Tartu. In 2014, he started his doctoral studies in Informatics at the University of Tartu. His current research themes include teaching programming and computational thinking in public school; career choices of students of computer science and information technology. He has worked as a mathematics and informatics teacher in a secondary school and as Assistant of Didactics of Informatics at the University of Tartu.

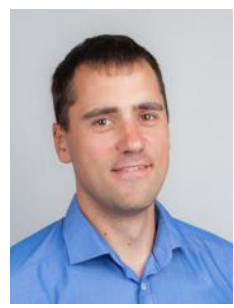

Heilo Altin was born in 1984. He got the master's degree in computer engineering from 2008. Now he continues his research in his $\mathrm{PhD}$ studies in education. His research area includes educational robotics and its effect on learning. Mr. Altin has been running the educational robotics program in Estonia since its beginning in 2008 . He has been organizing teacher trainings, competitions and developing materials, using robotics in physics classes in schools and running extracurricular activities in robotics at secondary school level for two years. His NGO, Robootika is also an operational partner in the FIRST LEGO League program.

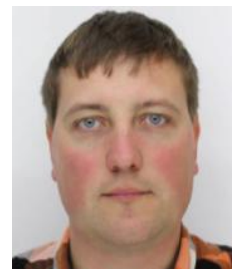

Ramon Rantsus was born in Tartu, Estonia, in 1984 He received his master of science degree in computer engineering in 2011 from the University of Tartu. Since 2009, he has been involved in the developmen of Educational Robotics in Estonia. His main job is to attract schools to robotics through schools visits, teacher trainings, different competitions and support them with educational robotics materials. Besides the activities in the University of Tartu, he is mostly active in the NGO Robootika, which is running different projects on educational robotics in Estonia, Latvia, Moldova and other EU countries. 